\title{
Prior cocaine exposure disrupts extinction of fear conditioning
}

\author{
Kathryn A. Burke, ${ }^{1,2}$ Theresa M. Franz, ${ }^{2}$ Nishan Gugsa, ${ }^{4}$ and \\ Geoffrey Schoenbaum $2,3,4,5$
}

\begin{abstract}
${ }^{1}$ Program in Neuroscience, University of Maryland School of Medicine, Baltimore, Maryland 21230, USA; ${ }^{2}$ Department of Anatomy and Neurobiology, University of Maryland School of Medicine, Baltimore, Maryland 21230, USA; ${ }^{3}$ Department of Psychiatry, University of Maryland School of Medicine, Baltimore, Maryland 21230, USA; ${ }^{4}$ Department of Psychology, University of Maryland, Baltimore County, Maryland 21230, USA
\end{abstract}

\begin{abstract}
Psychostimulant exposure has been shown to cause molecular and cellular changes in prefrontal cortex. It has been hypothesized that these drug-induced changes might affect the operation of prefrontal-limbic circuits, disrupting their normal role in controlling behavior and thereby leading to compulsive drug-seeking. To test this hypothesis, we tested cocaine-treated rats in a fear conditioning, inflation, and extinction task, known to depend on medial prefrontal cortex and amygdala. Cocaine-treated rats conditioned and inflated similar to saline controls but displayed slower extinction learning. These results support the hypothesis that control processes in the medial prefrontal cortex are impaired by cocaine exposure.
\end{abstract}

Drug addiction is characterized by compulsive behavior, exemplified by excessive seeking and taking of drugs even in the face of adverse consequences. Such behavior has been hypothesized to result from drug-induced neuroadaptations in prefrontallimbic circuits that normally control behavior (Robinson and Kolb 1999; Vanderschuren and Kalivas 2000; Everitt et al. 2001; Robinson et al. 2001). Consistent with this proposal, studies on addicts and animals exposed to psychostimulants have shown that drug exposure causes relatively long-lasting impairments in the control of behavior, particularly in tasks that depend on the orbital prefrontal cortices (Bechara et al. 2001; Jentsch et al. 2002; Schoenbaum et al. 2004; Kantak et al. 2005; Schoenbaum and Setlow 2005). However, there has been relatively little investigation of the effects of psychostimulant exposure on behaviors that depend on the medial prefrontal cortex (MPFC), despite observations that the MPFC is critical to suppressing inappropriate responses (Morgan et al. 1993; Birrell and Brown 2000; Quirk et al. 2000) and reports that psychostimulants induce widespread changes in MPFC (Robinson and Kolb 1999, 2004; Trantham et al. 2002; Kalivas 2004; Kalivas et al. 2005).

Such effects in the MPFC might also be expected to have a significant impact on normal behavioral flexibility. Studies of the effects of MPFC lesions in tasks such as attentional set-shifting and extinction of fear conditioning have shown that this region is critical to redirecting behavior in the face of competing or contradictory information. Thus, in each of these learning paradigms, MPFC is not necessary for initial learning but becomes critically important when rats must change their behavior when the correct response becomes uncertain or ambiguous (Morgan et al. 1993; Birrell and Brown 2000; Quirk et al. 2000). If psychostimulant-induced neuroadaptations in MPFC are functionally significant, then we should observe changes in performance in these tasks in drug-experienced rats.

To test this hypothesis, we trained rats that had been previously exposed to cocaine in a fear conditioning and extinction task. Table 1 gives an outline of the order of experimental procedures. The task was similar to that employed by Quirk and

\footnotetext{
${ }^{5}$ Corresponding author.

E-mail schoenbg@schoenbaumlab.org; fax (410) 706-2512.

Article published online before print. Article and publication date are at http:// www.learnmem.org/cgi/doi/10.1101/lm.216206.
}

colleagues (2000) to test MPFC function, except that prior to extinction, half of the rats underwent an inflation procedure to increase the incentive value of the shock stimulus (Rescorla 1974). Inflation causes an increase in subsequent conditioned responding, which depends on basolateral amygdala (Fanselow and Gale 2003).

Twenty-three 3-mo-old male Long-Evans rats (300-350 g, Charles River Labs) served as subjects. Testing was conducted in standard-sized behavioral boxes, $12 \times 10 \times 12$ inches, from Coulbourn Instruments. The front and back of the boxes are made of clear acrylic, and the sides and top of the boxes are made of aluminum. The floors of the chambers were made of 0.25 -inch rods spaced 1 inch apart, which could be electrified to deliver footshocks. Photocell activity monitors were mounted on the top of the boxes to record activity levels. Data were collected by computer using software for behavioral testing (GS2, Coulbourn Instruments). In addition, a low-light CCD camera was mounted within each shell to view the inside of each box. Output from the cameras was then digitized and recorded on a DVD along with a $1-\mathrm{Hz}$ timing pulse. For all training except for inflation, these boxes were enclosed in sound- and light-resistant shells. The boxes were configured with cues, food cups, and response levers, obtained from Coulbourn Instruments, as required for the different training procedures described below. Data regarding locomotor activity, food cup responding, and bar pressing were processed by computer (GS2, Coulbourn Instruments) and subsequently analyzed in Matlab. During conditioning and extinction, we calculated rates of bar pressing for the pre-CS and CS periods for each trial, and a suppression ratio was calculated from these data for each rat on each trial as (bar pressing pre-tone-tone $) /($ bar pressing pre-tone+tone). Freezing during fear conditioning and extinction was scored manually by observers watching the sessions recorded on DVDs. Freezing was defined as an absence of movement, except for respiratory and whisking movements, in an alert rat. It was scored in 1-sec increments, using the timing pulses on the DVD recordings, and was subsequently averaged during the pre-CS and CS periods. Measures were compared by ANOVA (Statistica) with post hoc testing where appropriate $(P<0.05)$.

Rats were food deprived ( $85 \%$ baseline) and then trained to bar press for sucrose food pellets ( $45 \mathrm{mg}$ sucrose pellets, Research Diets) on a VI60 (variable interval, $60 \mathrm{sec}$ ) schedule until they 
Table 1. Outline of experimental procedures

\begin{tabular}{|c|c|c|c|c|c|c|c|}
\hline Group & $\begin{array}{l}\text { Bar press } \\
\text { training }\end{array}$ & $\begin{array}{c}\text { Cocaine } \\
\text { sensitization }\end{array}$ & Withdrawal & Retraining & $\begin{array}{c}\text { Fear } \\
\text { conditioning }\end{array}$ & & \\
\hline Saline & FR1-VI60 (1 wk) & Saline (2 wk) & $3 \mathrm{wk}(\mathrm{HC})$ & VI60 (1 wk) & Habit. (CS) & Cond. (CS-US) / No inflation & Ext. (CS) I and II \\
\hline Cocaine & FR1-VI60 (1 wk) & Cocaine (2 wk) & 3 wk (HC) & VI60 (1 wk) & Habit. (CS) & Cond. (CS-US) $\begin{array}{l}\text { Inflation }\left(U^{\mathrm{a}}\right) \\
\text { No inflation } \\
\text { Inflation }\left(\mathrm{US}^{\mathrm{a}}\right)\end{array}$ & $\begin{array}{l}\text { Ext. (CS) I and II } \\
\text { Ext. (CS) I and II } \\
\text { Ext (CS) I and II }\end{array}$ \\
\hline
\end{tabular}

$\mathrm{HC}$ indicates home cage; CS, conditioned stimulus; US, unconditioned stimulus $/ 0.5 \mathrm{~mA}$ shock

a US, unconditioned stimulus/3 mA shock

achieved a response rate of $\sim 20$ responses per minute in a 20-30 min session (Table 1). Once all of the rats had met this criterion, they were divided into saline-treated $(n=11)$ and cocaine-treated $(n=12)$ groups. Response rates in these two groups did not differ during the final $4 \mathrm{~d}$ of training (saline $=21.7$; cocaine $=20.6$; $F=0.582, P>0.453)$.

Prior to fear conditioning, all rats that had been trained to bar press for food pellets underwent sensitization to cocaine (Table 1). For this, rats in the cocaine-treated group received $14 \mathrm{~d}$ of cocaine $(30 \mathrm{mg} / \mathrm{kg}$, i.p.); rats in the saline-treated group received a similar volume of saline. Following each injection, the rats were immediately put into the operant boxes for $1 \mathrm{~h}$ to record locomotor activity levels (Coulbourn Instruments). Cocaine-treated rats exhibited a significant increase in locomotor activity (Fig. 1, left side). ANOVA revealed significant main effects of treatment $\left(F_{(1,19)}=5.55, P<0.001\right)$ and session $\left(F_{(13,247)}=9.74, P<0.001\right)$, as well as a significant interaction between these two factors $\left(F_{(13,247)}=5.76, P<0.001\right)$. Post hoc testing revealed no differences between the two groups before treatment (day $0, F_{(1,19)}=0.818, P>0.37$ ) but a significant difference at the end of treatment (day $14, F_{(1,19)}=31.22, P<0.001$ ).

Twenty-one days following cocaine treatment, rats were retrained to bar press for food and then tested in the fear condi-

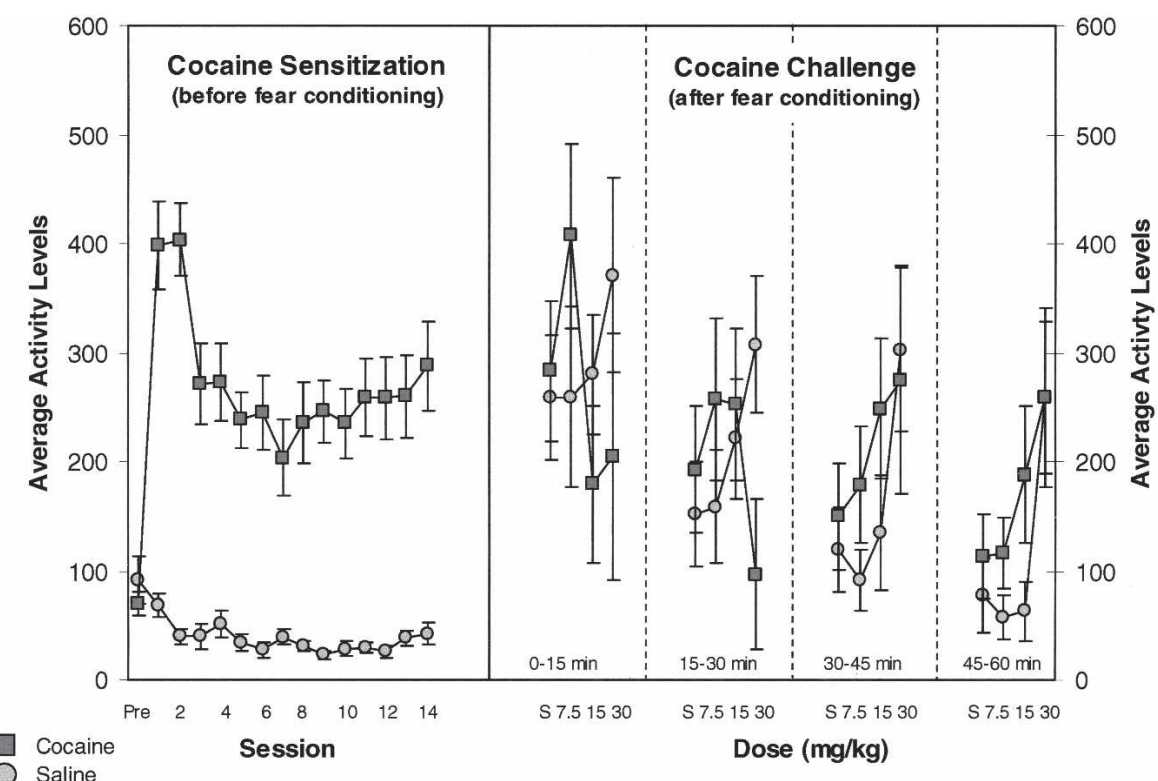

Figure 1. Effect of cocaine on locomotor activity. Data on the left show mean locomotor activity levels ( $5 \mathrm{~min}$ ) during the hour immediately following each injection of cocaine (30 mg/kg i.p.) or saline over the $14 \mathrm{~d}$ of sensitization. Data on the right show mean locomotor activity levels $(5 \mathrm{~min})$ for cocaine- and saline-treated rats during the cocaine challenge test, in which increasing doses of cocaine were administered to both groups. Data are shown in ascending 15-min blocks during each 1-h session for each injection (saline, $7.5 \mathrm{mg} / \mathrm{kg}, 15.0 \mathrm{mg} / \mathrm{kg}, 30.0 \mathrm{mg} / \mathrm{kg}$ ). Cocaine-treated rats exhibited greater sensitivity to cocaine in the challenge test. This was evident as increased activity to lower doses, particularly at $30-45$ and $45-60$ min into the session. tioning and extinction task (Table 1). Conditioning and extinction training was superimposed on a VI60 schedule of bar pressing for food. Conditioning began with habituation, which consisted of four presentations of the tone alone for $30 \mathrm{sec}(80$ $\mathrm{dB}, 4 \mathrm{kHz}$ ). Immediately following these four trials, the same tone was presented six times paired with a mild footshock, which consisted of a $0.5-\mathrm{mA}$ current delivered to the floor of the training chamber for $0.5 \mathrm{sec}$, terminating with the tone.

As illustrated in Figure 2, cocaine- and saline-treated rats showed similar conditioning of both measures to the tone cue. Consistent with this interpretation, ANOVAs demonstrated significant main effects of trial for both freezing $\left(F_{(5,95)}=65.96\right.$, $P<0.001)$ and conditioned suppression $\left(F_{(5,95)}=35.4, P<0.001\right)$. However there were no significant main effects or interactions involving treatment on either freezing $\left(F_{(1,19)}=0.216, P>0.64\right.$; $\left.F_{(5,95)}=1.33, P>0.25\right)$ or suppression behavior $\left(F_{(1,19)}=2.89\right.$, $\left.P>0.104 ; F_{(5,95)}=0.646, P>0.66\right)$. Further analysis of responding on the final day of conditioning showed that cocaine-treated rats froze at similar levels as saline-treated animals $(61.5 \%$ vs. $64.3 \%$, respectively; $\left.F_{(1,19)}=0.083, P>0.77\right)$, and displayed similar suppression ratios compared with controls $(0.88$ and 0.92 , respectively; $\left.F_{(1,19)}=0.046, P>0.83\right)$.

After fear conditioning, rats in the cocaine- and salinetreated groups were divided in half to make four groups: cocaine inflated $(n=6)$, cocaine noninflated $(n=6)$, saline inflated $(n=6)$, and saline noninflated $(n=5)$. Rats were assigned to these groups so that there were no differences between inflated and noninflated groups in either conditioned freezing $\left(F_{(1,19)}=1.159, P>0.29\right)$ or suppression behavior $\left(F_{(1,19)}=0.057, P>0.81\right)$. Approximately $24 \mathrm{~h}$ after fear conditioning, rats in the inflated groups were placed into a new environment, not used in the conditioning procedure, and received three unscheduled shocks at six times the intensity of the original shock ( $3 \mathrm{~mA}$ for $0.5 \mathrm{sec}$ ) in a procedure modified from Rescorla (1974) (Table 1). Shocks were delivered at 4-min intervals on average; there were no tone deliveries or other cues that would allow the rats to predict the shock. Shocks were delivered by computer in a modified shock box located in a new room and lacking a soundproof enclosure. Rats in the noninflated groups received comparable handling but no footshocks.

Approximately $24 \mathrm{~h}$ after inflation (48 $\mathrm{h}$ after conditioning), all rats began extinction training (Table 1). Extinction consisted of two sessions conducted over 


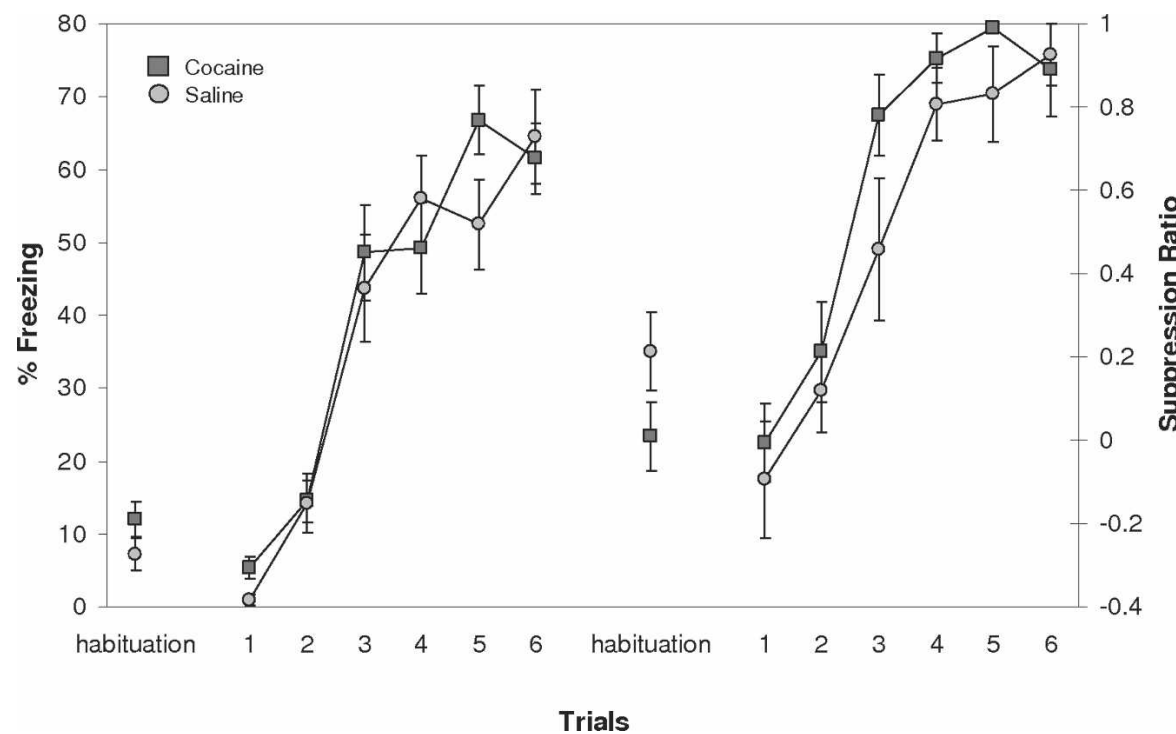

Figure 2. Effect of cocaine on conditioned freezing and suppression at the end of habituation and during fear conditioning. Freezing is shown as the percentage of time during the tone CS that the rat spent freezing; suppression is shown as a ratio comparing the bar pressing during the CS with bar pressing during the pre-CS period. A value of one indicates complete suppression (no bar pressing) during the CS, whereas a value of zero indicates no difference in bar pressing rates in the pre-CS period and during to the CS. There was no effect of cocaine treatment on either behavior.

two consecutive days, with 16 presentations of tone alone in each session with no shock. As shown in Figure 3, saline- and cocaine-treated rats extinguished both conditioned freezing and suppression on day 1 of extinction. However cocaine-treated rats extinguished more slowly compared with controls. ANOVA confirmed this result, revealing significant main effects of trial on freezing $\left(F_{(15,285)}=27.69, P<0.001\right)$ and on conditioned suppression $\left(F_{(15,285)}=11.5, P<0.001\right)$, as well as a significant inter- action between treatment $\times$ trial for freezing $\left(F_{(15,285)}=3.0195, P<0.001\right)$, and a significant main effect of treatment on conditioned suppression $\left(F_{(1,19)}=8.36, P<0.01\right)$. Although there was no effect of cocaine treatment on day 2 of extinction on freezing behavior $\left(F_{(1,21)}=0.25, P>0.6229\right)$, there was a significant main effect of treatment on suppression behavior as shown in Figure 3 $\left(F_{(1,21)}=8.09, P<0.001\right)$.

We also examined the effect of inflation on conditioned responding during extinction on day 1 . As Figure 4 illustrates, inflated rats froze more than did noninflated controls, particularly early in the extinction session. This timing differs from extinction learning, which appears later in the session, and is consistent with the fact that inflation affects previously acquired learning. The effect of inflation did not differ between cocaine- and saline-treated rats. Consistent with this interpretation, an ANOVA indicated a significant interaction between inflation $x$ trial $\left(F_{(15,285)}=2.66, P<0.001\right)$ but no interaction between inflation $\times$ treatment $\left(F_{(1,19)}=0.08573, P>0.77\right)$. Note that there was no effect of inflation on suppression behavior, which is also shown in Figure 4 (no main effect of inflation, $F_{(1,19)}=0.181$, $P>0.67$ and no significant interaction between inflation $\times$ trial, $\left.F_{(15,285)}=0.694, P>0.79\right)$.

To confirm sensitization after behavioral testing, we administered i.p. injections of saline and 7.5, 15.0, and $30.0 \mathrm{mg} / \mathrm{kg}$ of cocaine to eight rats in each of the inflated and noninflated groups at the completion of extinction training (Fig. 1, right

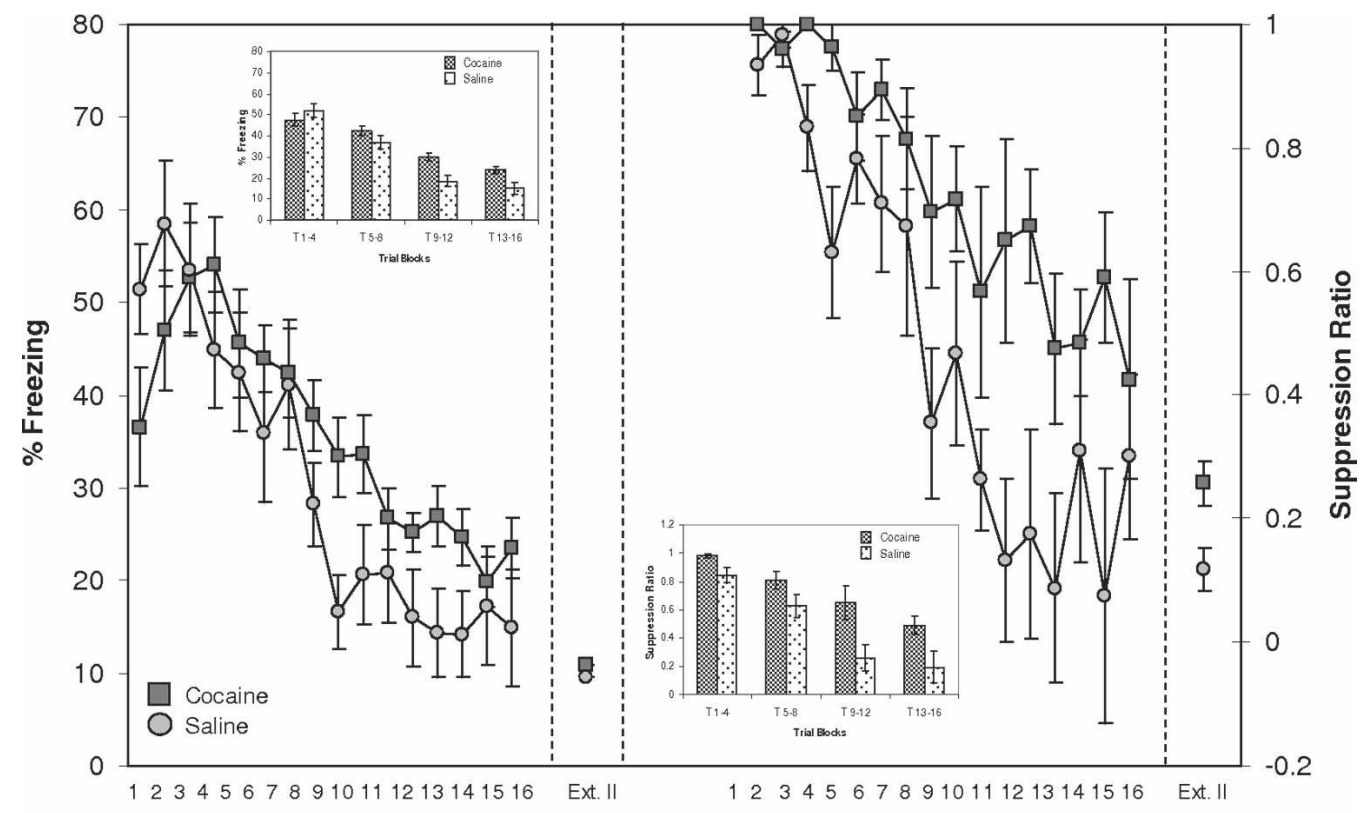

Extinction Trials

Figure 3. Effect of cocaine on extinction of conditioned freezing and suppression. Although cocaine- and saline-treated rats extinguished conditioned freezing and suppression, cocaine-treated rats were significantly slower to extinguish both behaviors. In addition, the cocaine-treated rats continued to show higher conditioned suppression on a second day of extinction training. 
A

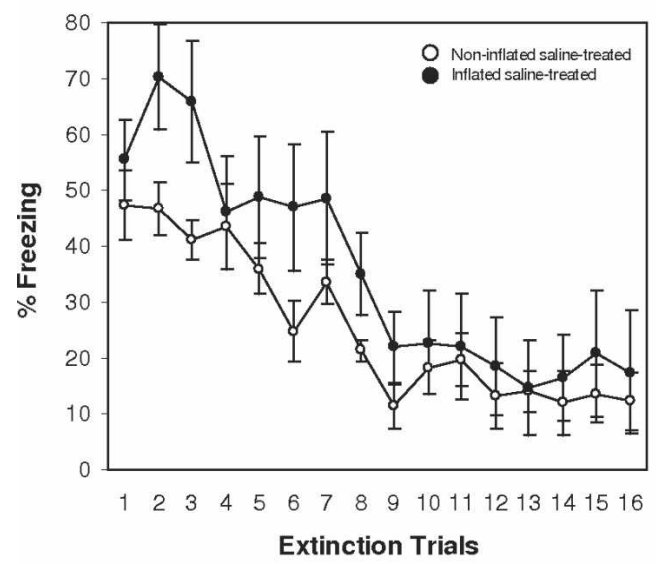

B

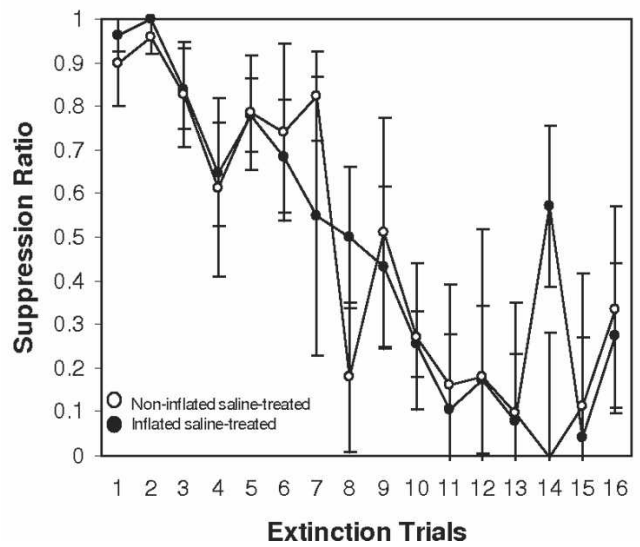

C

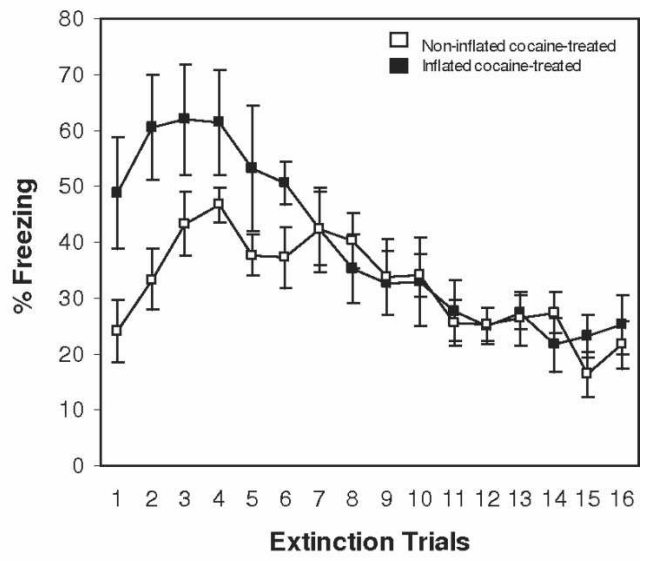

D

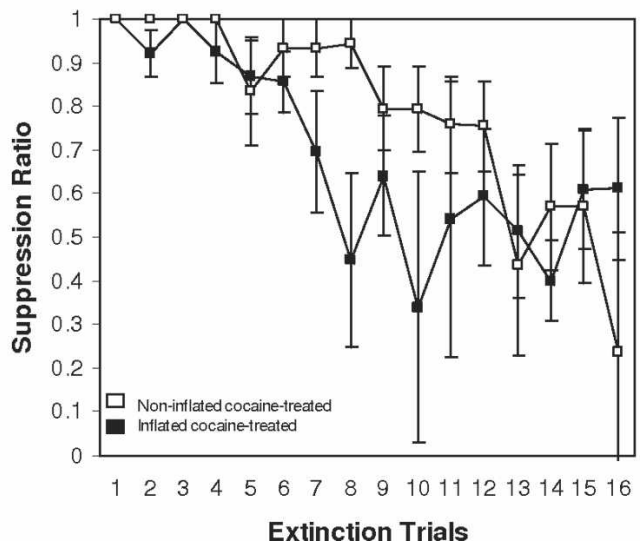

Figure 4. Effect of inflation of conditioned freezing and conditioned suppression in saline-treated $(A, B)$ and cocaine-treated $(C, D)$ rats. Inflated rats in both groups froze significantly more than noninflated rats, particularly at the beginning of extinction; there was no effect of cocaine. There appeared to be no effect of inflation on suppression in either group. Note that the effect of cocaine treatment on extinction of conditioned freezing and suppression, shown in Figure 2, was evident here in both inflated and noninflated rats.

side). Brains were harvested from the remaining rats in each group for use in another study and thus could not be re-exposed to cocaine. Nevertheless, in the rats that we tested, those that had been previously treated with cocaine exhibited increased sensitivity to the locomotor activating effects of the challenge injections compared with saline controls. As illustrated in Figure 1, this was evident as increased activity at lower doses, particularly in the 5-min blocks from 30-60 min post-injection. Consistent with this interpretation, ANOVA revealed significant interactions between treatment and 5-min block $\left(F_{(11,154)}=4.17, P<0.001\right)$ and between treatment, dose, and block $\left(F_{(33,462)}=3.44\right.$, $P<0.001)$.

We now know a great deal about the brain circuit that mediates fear conditioning and extinction of fear (LeDoux et al. 1990; Campeau and Davis 1995; Fendt and Fanselow 1999; Amorapanth et al. 2000; Fanselow and Gale 2003; Maren and Quirk 2004; Sotres-Bayon et al. 2004). Associations linking conditioned stimuli and fear-producing events are thought to be formed in the basolateral complex of amygdala (ABL) and then expressed through excitatory output to central nucleus. In addition, there is evidence that central nucleus operates in parallel to encode motivating aspects of fear-producing conditioned stimuli (Killcross et al. 1997; Balleine and Killcross 2006). Our results may reflect effects of cocaine within $\mathrm{ABL}$ and central nucleus or downstream regions that make such learning resistant to extinction. Such speculation would be consistent with reports that drug-exposed animals respond more strongly in other tasks that depend on these regions (Jentsch and Taylor 1999; Wyvell and Berridge 2001; Di Ciano and Everitt 2004). Enhanced transfer of the motivational effects of an appetitive Pavlovian cue to an instrumental response in amphetamine-sensitized rats is particularly interesting in this regard (Wyvell and Berridge 2001), since suppression of instrumental responding by the aversive cue in the current report may reflect a similar transference (Balleine and Killcross 2006).

Yet an isolated effect of cocaine on processing of fear memories within amygdala would not seem entirely consistent with the normal performance of cocaine-treated rats during conditioning and inflation, both of which are critically dependent on subregions within amygdala. Although previous studies have found effects of cocaine treatment on fear conditioning, it is difficult to separate effects of cocaine on locomotor activity from effects on conditioned behavior. Indeed, in one report, impaired freezing was dependent on locomotor sensitization, raising the question of whether lower levels of freezing might have reflected the activating effects of cocaine rather than impaired conditioning (Morrow et al. 1995), and in the second, enhanced conditioned startle was observed but only when conditioning was con- 
ducted in the same environment as sensitization (Gordon and Rosen 1999). As with declines in freezing, the increase in startle may have reflected the activating effects of cocaine since the sensitized rats also startled more in the absence of the CS. Here we saw no effect of cocaine on conditioning or inflation, suggesting that the processing of fear associations within amygdala is largely intact after cocaine exposure. Our ability to separate locomotor effects of cocaine from conditioning may have reflected the varied training that these rats received in the test boxes, including bar press training, sensitization, and then fear conditioning. These results indicate that if impaired extinction does result from disrupted processing in amygdala, it is clearly a rather selective effect.

Instead it seems more likely that impaired extinction reflects weaker control over the expression of this information by the MPFC, either due to changes in the MPFC or due to alterations in how the MPFC interacts with amygdala (or even areas downstream in ventral striatum/extended amygdala). It is well documented that cocaine exposure causes relatively long-lasting changes in structure and function in the MPFC. For example, rats sensitized to or trained to self-administer psychostimulants exhibit changes in $\mathrm{G}$ protein and dopaminergic functions that are proposed to disrupt normal mechanisms of plasticity. Furthermore, exposure to psychostimulants is associated with alterations in normal gating mechanisms and increases in dendritic complexity in the MPFC (Robinson and Kolb 1999; Trantham et al. 2002; Ferrario et al. 2003; Kalivas 2004; Kalivas et al. 2005).

The infralimbic area (IL) within the MPFC sends excitatory projections to $\mathrm{ABL}$, particularly to a population of GABAergic interneurons, known as the intercalated cells (McDonald et al. 1996). These projections are thought to suppress the expression of the fear memory by gating the flow of information from ABL to central nucleus. Thus IL neurons fire to fear-associated cues after extinction training and manipulations of this region that disrupt information processing or memory consolidation interfere with extinction. In addition, microstimulation of IL designed to replicate the effects of training has been shown to promote extinction (Milad and Quirk 2002). These data indicate that the expression of fear memories in subcortical regions is modulated by output from the MPFC (Milad and Quirk 2002; Quirk et al. 2003).

Clearly, enhanced responding to fear-associated cues during extinction learning might reflect the impact of drug-induced changes on the ability of the MPFC to modulate encoding in amygdala. Indeed our results are similar to results presented in abstract form (Torres-Reveron et al. 2000), in which they reported poor recall of extinction conducted on the same day as conditioning in sensitized rats. Effects of psychostimulants on the ability of prefrontal control mechanisms to modulate learning in downstream associative learning nodes, such as amygdala, would give rise to overresponding to particularly salient cues (Kalivas et al. 2005), such as the tone in the present experiment, appetitive Pavlovian cues used in other experiments after drug exposure (Jentsch and Taylor 1999; Wyvell and Berridge 2001; Di Ciano and Everitt 2004), or drug-associated cues in addiction studies (Grimm et al. 2001; Lu et al. 2005). Note that the enhanced responding would be driven by learning in these downstream nodes and thus is susceptible to manipulations of these areas known to disrupt learning. For example, established cocaine-seeking behavior is sensitive to manipulations of ABL that affect reconsolidation (Lee et al. 2005). However, by this model, the primary deficit would be not in the downstream regions but rather in the ability of prefrontal areas to normally modulate encoding in these downstream regions. In support of this idea, we have recently found that ABL neurons in cocaine-treated rats exhibit abnormally persistent encoding of the learned signifi- cance of odor cues after reversals in an odor discrimination task (Calu et al. 2005), an effect we have previously observed in rats with prefrontal lesions (Saddoris et al. 2005).

Interestingly, cocaine-exposure did not affect inflation of conditioned freezing in the current study. Inflation is a postconditioning procedure that tests the ability of the animal to adjust conditioned responding after an increase in the aversiveness of the footshock US. On first consideration, this procedure would seem analogous to reinforcer devaluation, which involves an assessment of conditioned responding after modification of the incentive value of an associated appetitive outcome. Normal performance in both settings is dependent on encoding of the original cue-outcome associations by ABL (Hatfield et al. 1996; Fanselow and Gale 2003; Pickens et al. 2003). Intact inflation in the current study would, therefore, be consistent with the interpretation that processing in ABL is relatively intact in cocaineexperienced rats, at least with regard to the encoding of the initial associations and the animal's ability to activate those associations with increased vigor. In addition, if cocaine treatment impairs both MPFC- and orbitofrontal cortex-dependent behaviors (Bechara et al. 2001; Jentsch et al. 2002; Schoenbaum et al. 2004; Kantak et al. 2005; Schoenbaum and Setlow 2005), then this result also suggests that inflation, unlike reinforcer devaluation, may not depend on prefrontal cortex. This highlights an important difference between a general ability to use incentive information to promote responding (inflation), which might be mediated by associative mechanisms in subcortical structures, and the ability to utilize incentive information to redirect responding (devaluation), which would require prefrontal cortex.

Finally, in considering the effects of inflation it is important to note that we did not see any effects of inflation on conditioned suppression, in either saline or cocaine-treated rats. To the best of our knowledge, this report provides the first demonstration that this transfer of the aversive properties of the fearproducing US to the instrumental bar pressing response is insensitive to the value of the US predicted by the Pavlovian cue. This is similar to what has been reported for appetitive Pavlovian-toinstrumental transfer. Further, dissociation of the effects of US inflation on conditioned freezing, which was increased, and on conditioned suppression, which remained unchanged, is consistent with the proposal that these properties of the Pavlovian CS are mediated by different circuits in the amygdala (Killcross et al. 1997; Balleine and Killcross 2006).

\section{Acknowledgments}

This work was supported by R01-DA015718 (G.S.) and T32-14074 (K.B.).

\section{References}

Amorapanth, P., LeDoux, J.E., and Nader, K. 2000. Different lateral amygdala outputs mediate reactions and actions elicited by a fear-arousing stimulus. Nat. Neurosci. 3: 74-79.

Balleine, B.W. and Killcross, S. 2006. Parallel incentive processing: An integrated view of amygdala function. Trends Neurosci. 29: 272-279.

Bechara, A., Dolan, S., Denburg, N., Hindes, A., Andersen, S.W., and Nathan, P.E. 2001. Decision-making deficits, linked to a dysfunctional ventromedial prefrontal cortex, revealed in alcohol and stimulant abusers. Neuropsychologia 39: 376-389.

Birrell, J.M. and Brown, V.J. 2000. Medial frontal cortex mediates perceptual attentional set shifting in the rat. J. Neurosci. 20: $4320-4324$.

Calu, D., Stalnaker, T.A., Roesch, M.R., and Schoenbaum, G. 2005. Basolateral amygdala generates abnormally persistent representations of predicted outcomes and cue value after cocaine exposure. Abstract Viewer/Itinerary Planner, Program No. 112.1. Society for Neuroscience, Washington, D.C.

Campeau, S. and Davis, M. 1995. Involvement of the central nucleus and basolateral complex of the amygdala in fear conditioning 
measured with fear-potentiated startle in rats trained concurrently with auditory and visual conditioned stimuli. J. Neurosci. 15: 2301-2311.

Di Ciano, P. and Everitt, B.J. 2004. Direct interactions between basolateral amygdala and nucleus accumbens core underlie cocaine-seeking behavior by rats. J. Neurosci. 24: 7167-7173.

Everitt, B.J., Dickinson, A., and Robbins, T.W. 2001. The neuropsychological basis of addictive behaviour. Brain Res. Brain Res. Rev. 36: 129-138.

Fanselow, M. and Gale, G. 2003. The amygdala, fear, and memory. Ann. N. Y. Acad. Sci. 985: 125-134.

Fendt, M. and Fanselow, M. 1999. The neuroanatomical and neurochemical basis of conditioned fear. Neurosci. Biobehav. Rev. 5: $743-760$.

Ferrario, C., Crombag, H.S., Gorny, G., Li, Y., Kolb, B., and Robinson, T.E. 2003. Amphetamine or cocaine self-administration experience produces persistent regionally-specific changes in spine density in prefrontal cortex of rats. Abstract Viewer/Itinerary Planner, Program No. 424.2. Society for Neuroscience, Washington, D.C.

Gordon, M.K. and Rosen, J.B. 1999. Lasting effect of repeated cocaine administration on acoustic and fear-potentiated startle in rats. Psychopharmacology 144: 1-7.

Grimm, J.W., Hope, B.T., Wise, R.A., and Shaham, Y. 2001. Incubation of cocaine craving after withdrawal. Nature 412: 141-142.

Hatfield, T., Han, J.S., Conley, M., Gallagher, M., and Holland, P. 1996. Neurotoxic lesions of basolateral, but not central, amygdala interfere with Pavlovian second-order conditioning and reinforcer devaluation effects. J. Neurosci. 16: 5256-5265.

Jentsch, J.D. and Taylor, J.R. 1999. Impulsivity resulting from frontostriatal dysfunction in drug abuse: Implications for the control of behavior by reward-related stimuli. Psychopharmacology 146: $373-390$.

Jentsch, J.D., Olausson, P., De La Garza, R., and Taylor, J.R. 2002. Impairments of reversal learning and response perseveration after repeated, intermittent cocaine administrations to monkeys. Neuropsychopharmacology 26: 183-190.

Kalivas, P.W. 2004. Glutamate systems in cocaine addiction. Curr. Opin. Pharmacol. 4: 23-29.

Kalivas, P.W., Volkow, N.D., and Seamans, J.K. 2005. Unmanageable motivation in addiction: A pathology in prefrontal-accumbens glutamate transmission. Neuron 45: 647-650.

Kantak, K.M., Udo, T., Ugalde, F., Luzzo, C., Di Pietro, N., and Eichenbaum, H.B. 2005. Influence of cocaine self-administration on learning related to prefrontal cortex or hippocampus functioning in rats. Psychopharmacology 181: 227-236.

Killcross, S., Robbins, T.W., and Everitt, B.J. 1997. Different types of fear-conditioned behaviour mediated by separate nuclei within amygdala. Nature 388: 377-380.

LeDoux, J.E., Cicchetti, P., Xagoraris, A., and Romanski, L.M. 1990. The lateral amygdaloid nucleus: Sensory interface of the amygdala in fear conditioning. J. Neurosci. 10: 1062-1069.

Lee, J.L., Di Ciano, P., Thomas, K.L., and Everitt, B.J. 2005. Disrupting reconsolidation of drug memories reduces cocaine-seeking behavior. Neuron 47: 795-801.

Lu, L., Hope, B.T., Dempsey, J., Liu, S.Y., Bossert, J.M., and Shaham, Y. 2005. Central amygdala ERK signaling pathway is critical to incubation of cocaine craving. Nat. Neurosci. 8: 212-219.

Maren, S. and Quirk, G. 2004. Neuronal signalling of fear memory. Nat. Rev. Neurosci. 5: 844-852.

McDonald, A.J., Mascagni, F., and Guo, L. 1996. Projections of the medial and lateral prefrontal cortices to the amygdala: A Phaseolus vulgaris leucoagglutinin study in the rat. Neuroscience 71: 55-75.
Milad, M.R. and Quirk, G.J. 2002. Neurons in medial prefrontal cortex signal memory for fear extinction. Nature 420: 70-74.

Morgan, M., Romanski, L., and LeDoux, J. 1993. Extinction of emotional learning: Contribution of the medial prefrontal cortex. Neurosci. Lett. 163: 109-113.

Morrow, B.A., Taylor, J.R., and Roth, R.H. 1995. Prior exposure to cocaine diminishes behavioral and biochemical responses to aversive conditioning: Reversal by glycine/ $N$-methyl-D-aspartate antagonist co-treatment. Neuroscience 69: 233-240.

Pickens, C.L., Saddoris, M.P., Setlow, B., Gallagher, M., Holland, P.C., and Schoenbaum, G. 2003. Different roles for orbitofrontal cortex and basolateral amygdala in a reinforcer devaluation task. J. Neurosci. 23: $11078-11084$.

Quirk, G.J., Russo, G.K., Barron, J.L., and Lebron, K. 2000. The role of ventromedial prefrontal cortex in the recovery of extinguished fear. J. Neurosci. 20: 6225-6231.

Quirk, G.J., Likhtik, E., Pelletier, J.G., and Pare, D. 2003. Stimulation of medial prefrontal cortex decreases the responsiveness of central amygdala output neurons. J. Neurosci. 23: 8800-8807.

Rescorla, R. 1974. Effect of inflation of the unconditioned stimulus value following conditioning. J. Comp. Physiol. Psychol. 86: 101-106.

Robinson, T.E. and Kolb, B. 1999. Alterations in the morphology of dendrites and dendritic spines in the nucleus accumbens and prefrontal cortex following repeated treatment with amphetamine or cocaine. Eur. J. Neurosci. 11: 1598-1604.

. 2004. Structural plasticity associated with exposure to drugs of abuse. Neuropharmacology 47: 33-46.

Robinson, T.E., Gorny, G., Mitton, E., and Kolb, B. 2001. Cocaine self-administration alters the morphology of dendrites and dendritic spines in the nucleus accumbens and neocortex. Synapse 39: 257-266.

Saddoris, M.P., Gallagher, M., and Schoenbaum, G. 2005. Rapid associative encoding in basolateral amygdala depends on connections with orbitofrontal cortex. Neuron 46: 321-331.

Schoenbaum, G. and Setlow, B. 2005. Cocaine makes actions insensitive to outcomes but not extinction: Implications for altered orbitofrontal-amygdalar function. Cereb. Cortex 15: 1162-1169.

Schoenbaum, G., Saddoris, M.P., Ramus, S.J., Shaham, Y., and Setlow, B. 2004. Cocaine-experienced rats exhibit learning deficits in a task sensitive to orbitofrontal cortex lesions. Eur. J. Neurosci. 19: 1997-2002.

Sotres-Bayon, F., Bush, D., and LeDoux, J. 2004. Emotional perseveration: An update on prefrontal-amygdala interactions in fear extinction. Learn. Mem. 11: 525-535.

Torres-Reveron, A., Jimenez-Rivera, C.A., and Quirk, G.J. 2000. Effects of prior cocaine sensitization on acquisition, extinction and recovery of conditioned fear. Abstract Viewer/Itinerary Planner, Program No. 485.18. Society for Neuroscience, Washington, D.C.

Trantham, H., Szumlinski, K.K., McFarland, K., Kalivas, P.W., and Lavin, A. 2002. Repeated cocaine administration alters the electrophysiological properties of prefrontal cortical neurons. Neuroscience 113: 749-753.

Vanderschuren, L.J. and Kalivas, P.W. 2000. Alterations in dopaminergic and glutaminergic transmission in the induction and expression of behavioral sensitization: A critical review of preclinical studies. Psychopharmacology 151: 99-120.

Wyvell, C.L. and Berridge, K.C. 2001. Incentive sensitization by previous amphetamine exposure: Increased cue-triggered "wanting" for sucrose reward. J. Neurosci. 21: 7831-7840.

Received February 7, 2006; accepted in revised form April 4, 2006. 


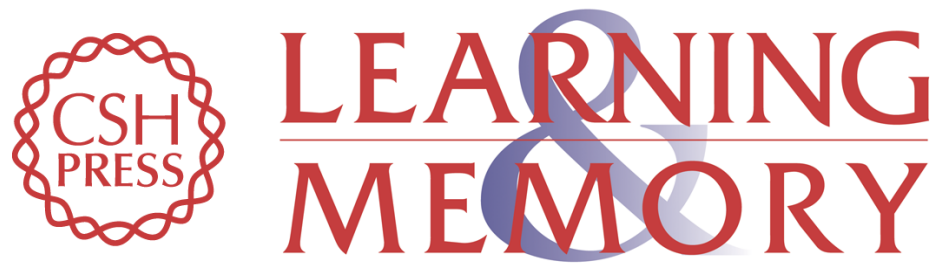

\section{Prior cocaine exposure disrupts extinction of fear conditioning}

Kathryn A. Burke, Theresa M. Franz, Nishan Gugsa, et al.

Learn. Mem. 2006, 13:

Access the most recent version at doi:10.1101/lm.216206

References This article cites 38 articles, 10 of which can be accessed free at: http://learnmem.cshlp.org/content/13/4/416.full.html\#ref-list-1

License

Email Alerting Receive free email alerts when new articles cite this article - sign up in the box at the Service top right corner of the article or click here. 